\title{
Fas Ligand Has a Greater Impact than TNF- $\alpha$ on Apoptosis and Inflammation in Ischemic Acute Kidney Injury
}

\author{
Kengo Furuichi ${ }^{a, b}$ Satoshi Kokubo ${ }^{b}$ Akinori Hara $^{b}$ Ryu Imamurac \\ Qiang Wang ${ }^{c}$ Shinji Kitajima ${ }^{b}$ Tadashi Toyama $^{\text {b }}$ Toshiya Okumura $^{b}$ \\ Kouji Matsushima ${ }^{f}$ Takashi Sudac Naofumi Mukaida $^{d}$ Shuichi Kaneko $^{\text {b }}$ \\ Takashi Wada ${ }^{\mathrm{e}}$ \\ ${ }^{a}$ Division of Blood Purification, Kanazawa University Hospital, ${ }^{b}$ Department of Disease \\ Control and Homeostasis, Faculty of Medicine, Divisions of ${ }^{\mathrm{C}}$ Immunology and Molecular \\ Biology, and ${ }^{\mathrm{d}}$ Molecular Bioregulation, Cancer Research Institute, and ${ }^{\mathrm{e}}$ Department of \\ Laboratory Medicine, Faculty of Medicine, Institute of Medical, Pharmaceutical and Health \\ Sciences, Kanazawa University, Kanazawa, and fDepartment of Molecular Preventive \\ Medicine, Graduate School of Medicine, The University of Tokyo, Tokyo, Japan
}

\section{Key Words}

Cytokine $\cdot$ Chemokine $\cdot$ Leukocyte $\cdot$ Tubular injury

\begin{abstract}
Background/Aim: Fas ligand (FasL) and tumor necrosis factor (TNF)- $\alpha$ are major pro-apoptotic molecules and also induce inflammation through cytokine and chemokine production. Although precise intracellular mechanisms of action have been reported for each molecule, the differential impact of these molecules on kidney injury in vivo still requires clarification. Methods: We explored the differential impact of FasL and TNF- $\alpha$ upon apoptosis and inflammation in ischemic acute kidney injury using neutralizing anti-FasL antibodies and TNF- $\alpha$ receptor 1 (TNFR1)-deficient mice. Results: TNFR1 deficiency was associated with a lesser anti-inflammatory effect upon leukocyte infiltration and tubular necrosis than treatment with anti-FasL antibody. Furthermore, the number of TUNEL-positive cells was significantly reduced in anti-FasL antibody-treated mice, whereas it was only partially diminished in TNFR1-deficient mice. In vitro studies confirmed these findings. FasL administration induced both apoptosis and cytokine/ chemokine production from cultured tubular epithelial cells. However, TNF- $\alpha$ had a limited effect upon tubular epithelial cells. Conclusion: In ischemic acute kidney injury, FasL has a greater impact than TNF- $\alpha$ on the apoptosis and inflammatory reaction through cytokine/chemokine production from tubular epithelial cells.

Copyright $\odot 2012$ S. Karger AG, Basel
\end{abstract}


Furuichi et al.: FasL and TNF- $\alpha$ in Ischemic Acute Kidney Injury

\section{Introduction}

Programmed cell death was originally thought to occur in the absence of inflammation, and was observed in both development and normal cell turnover. In contrast to apoptosis, unscheduled cell death was thought to induce inflammation with necrosis observed in systemic or local acute injury. However, several studies have indicated that apoptosis is a biological consequence of acute injury and may contribute to the inflammatory response [1-4]. Consistent with these suggestions, the inhibition of apoptosis may protect tissue against inflammatory damage [4-6].

Fas ligand (FasL) and tumor necrosis factor (TNF)- $\alpha$ are two key pro-apoptotic molecules and are expressed by inflammatory cells as well as by resident cells. These molecules may also induce inflammation through the production of various cytokines and chemokines $[2,7-9]$. Several previous reports indicated that FasL/Fas is involved in the pathogenesis of acute ischemic kidney injury via tubular apoptosis and necrosis $[11,12]$. Indirect evidence has also reported a role of TNF- $\alpha$ in acute ischemic kidney injury $[13,14]$. However, the differential impact of these two molecules on apoptosis and inflammation in ischemic kidney injury in vivo remains unclear.

In the present study, we explored the differential impact of FasL and TNF- $\alpha$ upon apoptosis and inflammation in a renal ischemia-reperfusion injury model using neutralizing anti-FasL antibodies and TNF- $\alpha$ receptor 1 (TNFR1)-deficient mice. Our observations indicated that FasL exerts a greater impact on apoptosis and inflammation than TNF- $\alpha$ in murine ischemic acute kidney injury in vivo.

\section{Materials and Methods}

\section{Animals}

Male wild type mice were purchased from Charles River, Japan Inc. (Atsugi, Japan). TNF-Rp55 KO mice (TNFR1), generated as previously described [15], had been backcrossed onto the $\mathrm{BALB} / \mathrm{c}$ background for 10 generations, and maintained under specific pathogenfree housing conditions. No significant differences in growth or weight were found between TNFR1 and wild type BALB/c mice. All male animals were used at 6-8 weeks of age. All procedures employed in the animal experiments complied with the standards set out in the Guidelines for the Care and Use of Laboratory Animals in Takara-machi Campus of Kanazawa University.

\section{Reagents}

FasL (WX1) and anti-FasL neutralizing $\mathrm{mAb}$ (FLIM58) were prepared as described previously [16-18]. Mouse TNF- $\alpha$ was purchased from R\&D Systems (Minneapolis, Minn., USA). FasL (WX1) comprises almost the complete extracellular region of FasL and efficiently kills mature T cells in freshly isolated mouse splenocytes or lymph node cells. Unlike naturally processed mouse soluble FasL, WX1 is biologically active [17].

\section{Renal Ischemia-Reperfusion Model}

After establishment of general anesthesia with diethyl ether and pentobarbital sodium, the left renal artery and vein of TNFR-1-deficient mice and wild type controls were exposed by flank incision and clamped for $60 \mathrm{~min}$. Kidneys that did not completely recover after unclamping, as assessed by restoration of normal color, were not included in the analysis. After releasing the clamp, the flank incision was closed in two layers with silk sutures. The animals received warm saline instilled into the peritoneal cavity during the 
procedure and were allowed to recover with free access to food and water. Sham surgery was performed in a similar manner, except the renal vessel clamp. A blocking study was performed in the same way as described previously [16]. Anti-FasL Ab or normal hamster $\operatorname{IgG}(5 \mathrm{mg} / \mathrm{ml}, 0.1 \mathrm{ml})$ was injected into the abdominal cavity $1 \mathrm{~h}$ before the occlusion of renal vessels.

\section{Immunohistochemistry}

One portion of the renal tissue was fixed in $10 \%$ buffered formalin, then embedded in paraffin, sectioned and stained with periodic acid-Schiff (PAS) reagent. The degree of tubular necrosis was quantified according to a semiquantitative scoring scale: 0 , normal kidney; 1 , minimal necrosis ( $<5 \%)$; 2 , mild necrosis (5-25\%); 3, moderate necrosis (25-75\%); 4, severe necrosis $(>75 \%)$ [19]. Interstitial infiltrating cells were counted in 20 randomly selected high power fields $(\times 400)$ of outer medulla.

Deparaffinized sections were treated with proteinase K (DAKO, Glostrup, Denmark) prior to immunostaining for F4/80, Fas and FasL. Endogenous peroxidase activity and nonspecific binding was blocked by Peroxidase-Blocking Reagent (DAKO), Biotin-Blocking System (DAKO) and Protein Block, Serum-Free (DAKO). Rat anti-mouse F4/80 monoclonal antibody (clone: BM8; eBioscience, San Diego, Calif., USA) and hamster anti-mouse Fas and FasL antibody (Pharmingen, Franklin Lakes, N.J., USA) were used to detect F4/80, Fas and FasL, respectively. Normal rat or hamster IgG were used as a negative control. Rat anti-F4/80 antibody or hamster anti-mouse Fas and FasL antibody were detected by biotinylated polyclonal anti-rat (DAKO) or anti-hamster (Pharmingen) antibodies and the LSAB+ system (peroxidase) (DAKO). After washing with PBS containing $0.01 \%$ Tween, sections were stained with 3,3'-diaminobenzidine (DAB) solution and counterstained with hematoxylin. TdT-mediated dUTP nick end labeling (TUNEL)-positive cells were detected by a modified TACS TdT DAB kit (R\&D Systems). After washing with PBS containing $0.01 \%$ Tween, positive cells were visualized by alkaline phosphatase and its substrate. Neutrophils were stained using alkaline phosphatase substrates kit II (SK-5200) as previously reported [20]. Infiltrating neutrophils and F4/80-positive and TUNEL-positive apoptotic cells were quantified in the outer medulla of the injured kidney and the data were expressed as cell number/high power fields (400× magnification).

\section{Proximal Tubular Cell Culture}

Immortalized murine proximal tubular cells [21] were cultured in DMEM containing $10 \%$ heat-inactivated FBS, $100 \mathrm{U} / \mathrm{ml}$ penicillin and $100 \mu \mathrm{g} / \mathrm{ml}$ streptomycin. Cells $\left(2 \times 10^{6} /\right.$ well) were incubated in a 12-well tissue culture plate for $24 \mathrm{~h}$ and then made quiescent by incubation with $0.1 \%$ FBS in DMEM for $24 \mathrm{~h}$. FasL (0-500 U/ml) and TNF- $\alpha(0-500 \mathrm{ng} / \mathrm{ml})$ were added to the medium and cells were incubated for $6,24,48$, or $96 \mathrm{~h}$ at $37^{\circ} \mathrm{C}$. After the incubation, the percentage of dead cells and chemokine expression was evaluated. Cells were incubated in $1 \mathrm{ml}$ of PBS containing $50 \mathrm{l} / \mathrm{ml}$ of propidium iodide (Sigma, St. Louis, Mo., USA) on ice for $10 \mathrm{~min}$. The dead cells were measured by a FACScan with CellQuest software (BD Biosciences, San Jose, Calif., USA).

\section{Cytokine Quantification}

Total RNA was extracted from the kidney and cells were cultured using the RNAqueous kit (Ambion Inc., Austin, Tex., USA). RNA was treated with deoxyribonuclease and purified with DNA-free (Ambion, Inc.). The RNA was quantified by absorbance at $260 \mathrm{~nm}$ in a spectrophotometer. cDNA was reverse-transcribed from $1 \mu \mathrm{g}$ of total RNA using a RETROscript kit (Ambion, Inc.). TNF- $\alpha$ mRNA was detected by 33 cycles of polymerase chain reaction (PCR). PCR was found to be linear between 20 and 35 cycles. The following primers were 
used for TNF- $\alpha$ : forward: TCTCATCAGTTCTATGGCCC, and reverse: GGGAGTAGACAAGGTACAAC. The mRNA expression of cytokines, chemokines, and the housekeeping gene glyceraldehyde-3-phosphate dehydrogenase (GAPDH) was analyzed using an MPCR kit (Maxim Biotech, Inc., San Francisco, Calif., USA) according to the manufacturer's protocol. Images of UV-illuminated agarose gels were captured, and the density of cDNA bands was analyzed using NIH Image software. PCR was found to be linear between 24 and 36 cycles, and 33 cycles were chosen for all results shown. Cytokine as well as chemokine mRNA levels were standardized by GAPDH signals and are expressed relative to the levels found in sham-operated mice.

Cytokine levels in cell culture supernatants were quantified using a Procarta Cytokine Profiling kit (Affymetrix, Santa Clara, Calif., USA), which uses xMAP technology (multianalyte profiling Luminex technology) to enable the detection and quantification of multiple protein targets simultaneously. Fluorescently encoded antibody beads were detected uniquely in a flow cytometer and five mouse cytokines [keratinocyte chemoattractant (KC), MCP1, MIP-1 $\alpha$, IL-1, IP-10] were evaluated.

\section{Statistical Analysis}

The mean and standard error of mean (SEM) were calculated on all the parameters determined in this study. Statistical analyses were performed using unpaired Student's t test, Kruskal-Wallis test and ANOVA test. $\mathrm{p}<0.05$ was accepted as statistically significant.

\section{Results}

TNF- $\alpha$, Fas and FasL Were Expressed in the Kidney after Ischemia-Reperfusion Injury

TNF- $\alpha$ mRNA expression was faintly detected in sham-operated kidneys from wild type mice but significantly upregulated following ischemia-reperfusion injury (fig. 1a). Similarly, the expression of Fas protein was also faint in sham-operated kidneys from wild type mice but was significantly upregulated after ischemia-reperfusion injury [fig. 1b(i, ii), c(i)]. Fas protein was mainly detected on tubular epithelial cells. In contrast to Fas, FasL expression was detected on epithelial cells in sham-operated kidneys from wild type mice. After ischemia, infiltrating cells were also positive for FasL [fig. 1b(iii, iv), c(ii)]. The number of Fas- and FasL-positive cells increased after ischemic kidney injury.

TNF- $\alpha$ and FasL Participated in Tissue Destruction after Ischemia-Reperfusion Injury

Interstitial cell infiltration and tubular necrosis are characteristic pathologic changes in renal ischemia-reperfusion injury. Tubular necrosis was evident after ischemic injury and peaked at $48 \mathrm{~h}$. TNFR1 deficiency had a minor effect on tubular necrosis. In contrast, treatment with anti-FasL Ab significantly prevented tubular necrosis [fig. 2a, c(i)]. Furthermore, treatment with anti-FasL Ab significantly reduced cytokine/chemokine expression and interstitial cell infiltration, especially neutrophil infiltration [fig. 2b, c(ii, iii)]. F4/80-positive macrophage infiltration was not affected by anti-FasL Ab administration [fig. 2c(iv)]. In contrast to the effect of anti-FasL Ab, TNFR1 deficiency did not show major effects on cytokine/chemokine expression or interstitial cell infiltration after ischemia [fig. 2b, c(i-iv)].

TNF- $\alpha$, Fas and FasL Participated in Apoptosis after Ischemia-Reperfusion Injury

The number of apoptotic TUNEL-positive cells significantly increased following ischemia (fig. 3a, b). The number of apoptotic cells was significantly diminished in TNFR1-deficient mice and anti-FasL Ab-treated mice with the anti-apoptotic effect being more evident 


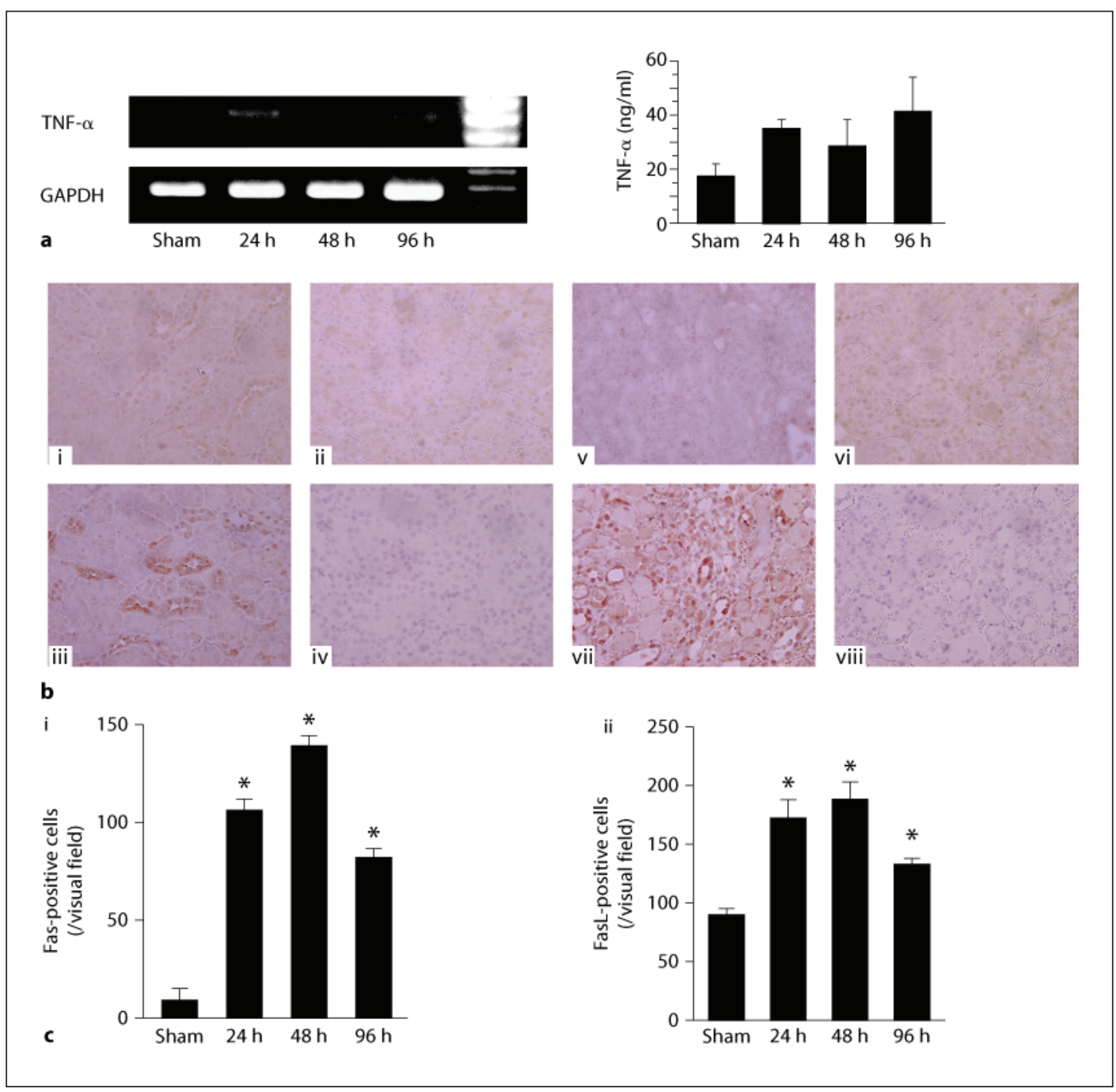

Fig. 1. TNF- $\alpha$ and FasL were upregulated in the ischemic injured kidney. a TNF- $\alpha$ mRNA and protein expression in the injured kidney were detected by RT-PCR and ELISA, respectively, at the indicated time points after ischemia-reperfusion injury. b Fas (i, ii, iii) and FasL (v, vi, vii) protein were detected by immunohistochemical staining on control, sham and injured kidney $24 \mathrm{~h}$ after reperfusion, respectively. Panels iv and viii indicate control IgG staining for Fas and FasL, respectively. c Quantification of Fas- (i) and FasL- (ii) positive cells in tissue sections was undertaken in sham-operated and wild type mice. Values are mean \pm SEM. Five animals were evaluated for each condition. Original magnification of all images is $400 \times .{ }^{*} \mathrm{p}<0.05$ compared with sham-operated wild type mice.

in anti-FasL Ab-treated mice. In addition, the combination of TNFR1 deficiency and antiFasL $\mathrm{Ab}$ treatment was not more protective than anti-FasL Ab treatment alone. These results were confirmed by the immunohistochemical staining of caspase 3 (fig. $3 \mathrm{c}, \mathrm{d}$ ). The number of caspase 3-positive cells significantly increased after ischemia and was reduced in TNFR1deficient mice and anti-FasL Ab-treated mice. Similar to TUNEL-positive cells, the deficiency of TNFR1 did not further reduce the number of caspase 3-positive cells in the injured kidney in mice that also received anti-FasL $\mathrm{Ab}$ treatment. 


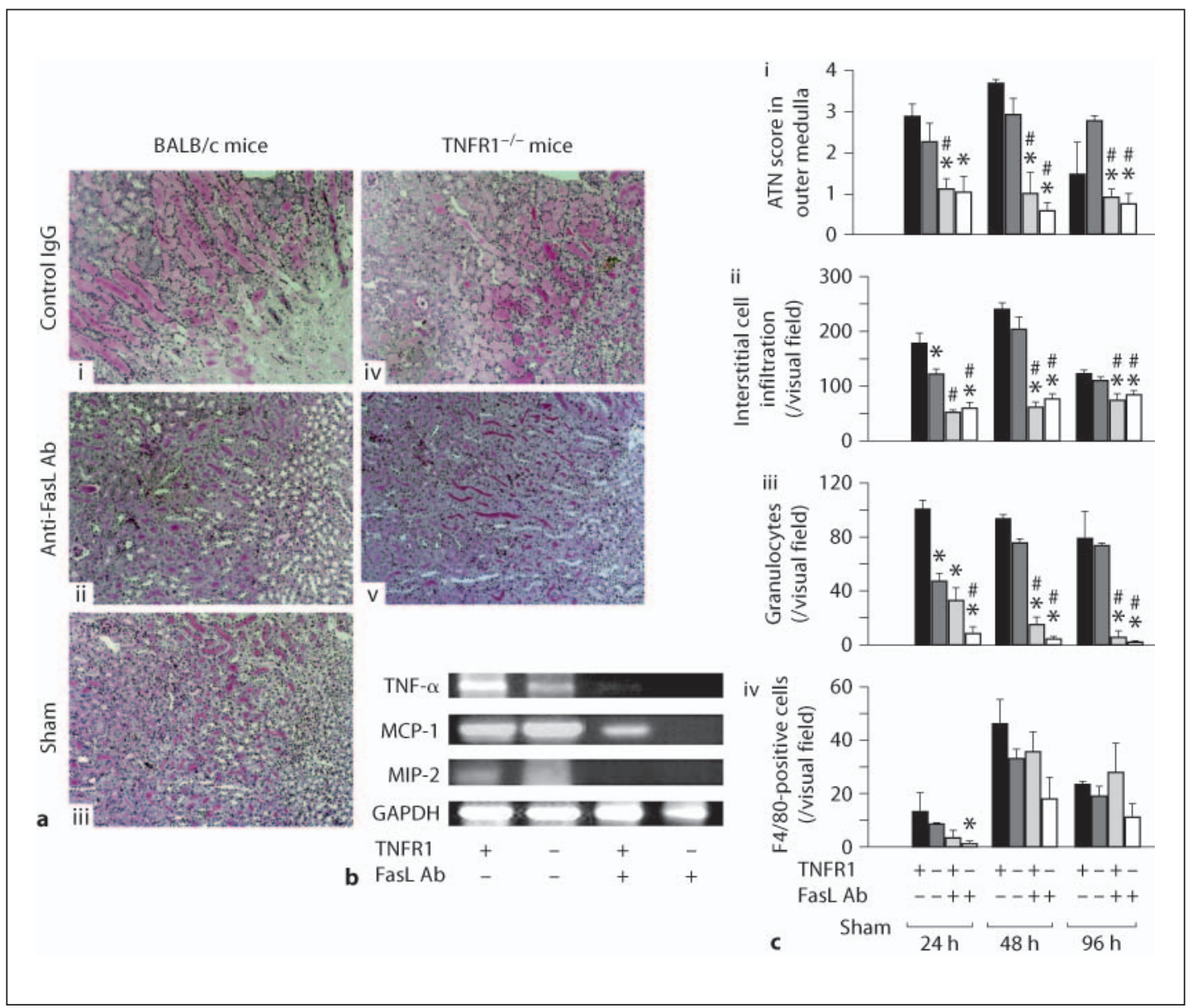

Fig. 2. Anti-FasL antibodies and TNFR1 deficiency reduced tubular necrosis and interstitial cell infiltration after ischemic kidney injury. a Histopathologic analysis. PAS-stained outer medulla of the left injured kidney is shown for wild type (i, ii, iii) and TNFR1-deficient (iv, v) mice with anti-FasL Ab treatment (ii, v) or control IgG treatment (i, iv) 48 h after ischemia reperfusion or sham operation (iii). b Cytokine and chemokine expression of injured kidney $48 \mathrm{~h}$ after reperfusion was detected by RT-PCR. c Quantification of the ATN score (i) and the numbers of interstitial infiltrating cells (ii), granulocytes (iii) and F4/80positive cells (iv) following ischemia. TNFR1+ = Wild type mice; TNFR1- = TNFR1-deficient mice; FasL+ = anti-FasL Ab-treated mice; FasL- = control IgG-treated mice. Values are means \pm SEM. Five animals were evaluated for each condition. Original magnification of all images is $400 \times .{ }^{*} \mathrm{p}<0.05$ compared with control IgG-treated wild type mice; ${ }^{\#} \mathrm{p}<0.05$ compared with TNFR1-deficient mice.

\section{TNF- $\alpha$ and FasL Induced Apoptosis and Cytokine/Chemokine Expression}

TNF- $\alpha$ induced limited apoptosis on cultured tubular epithelial cells whilst FasL induced significant apoptosis in a dose-dependent manner at $24 \mathrm{~h}$ with the pro-apoptotic effect continuing until $48 \mathrm{~h}$ (fig. 4). Unstimulated cultured tubular epithelial cells produced minimal cytokines and chemokines. However, the protein and mRNA expression of cytokines and chemokines significantly increased following FasL stimulation. The protein expression of KC peaked at $6 \mathrm{~h}$ whilst MIP-1 $\alpha$ and IL-1 peaked at $24 \mathrm{~h}$. MCP-1 and IP-10 retained high protein expression levels throughout the experimental period. TNF- $\alpha$ weakly upregulated cytokine and chemokine expression at all time points examined (fig. 5). 


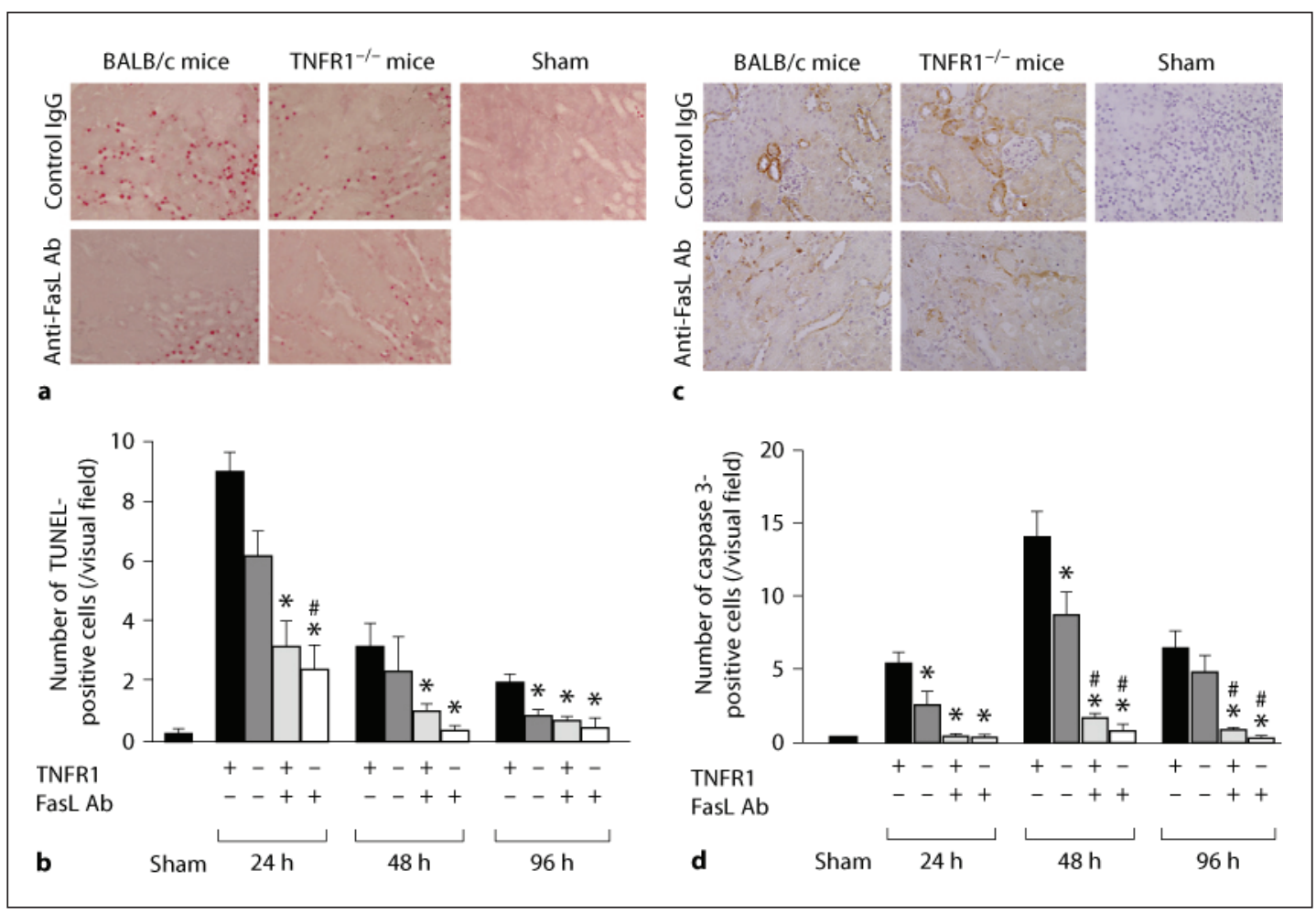

Fig. 3. Anti-FasL antibody treatment and TNFR1 deficiency reduced apoptosis after ischemic kidney injury. Kidney sections obtained $24 \mathrm{~h}$ following ischemia were stained for TUNEL and caspase 3. a, c Representative results for kidneys from indicated mice $(400 \times$ magnification). b, d Quantification of the number of TUNEL-positive and caspase 3-positive cells. Values are means \pm SEM. TNFR1+ = Wild type mice; TNFR1- = TNFR1-deficient mice; FasL $+=$ anti-FasL Ab-treated mice; FasL- = control IgG-treated mice. ${ }^{*} \mathrm{p}<0.05$ compared with control IgG-treated wild type mice; ${ }^{\#} \mathrm{p}<0.05$ compared with TNFR1-deficient mice.

\section{Discussion}

Apoptosis and inflammation play a key role in the pathogenesis of ischemic acute kidney injury. Although the FasL/Fas and TNF- $\alpha$ /TNFR are two fundamental pathways involved in many pathological conditions, their differential effect on apoptosis and inflammation in acute kidney injury has not been investigated in vivo models thus far. Our study indicated that neutralizing anti-FasL Ab treatment diminished inflammatory cell infiltration, tubular necrosis and apoptosis more markedly than TNFR1 deficiency. These findings were confirmed in cultured tubular epithelial cells and these data emphasize the important impact of the FasL/Fas system on ischemic kidney injury.

Neutralizing anti-FasL Ab treatment resulted in more significant anti-inflammatory effects than TNFR1 deficiency, including a more marked reduction in inflammatory cell infiltration, chemokine production and tubular necrosis in vivo. One explanation for these findings would be the extensive upregulation of Fas and FasL expression on tubular epithelial cells after reperfusion. FasL mRNA and protein expression were reported to be increased following ischemia [22] with cytokines such as TNF- $\alpha$, IL- $1 \alpha$ and - $\beta$ acting to upregulate cell surface Fas in renal cells [23]. The increased Fas and FasL expression exacerbated the severity of ischemic kidney injury [11,24]. Furthermore, tubular epithelial cells co-express Fas and 


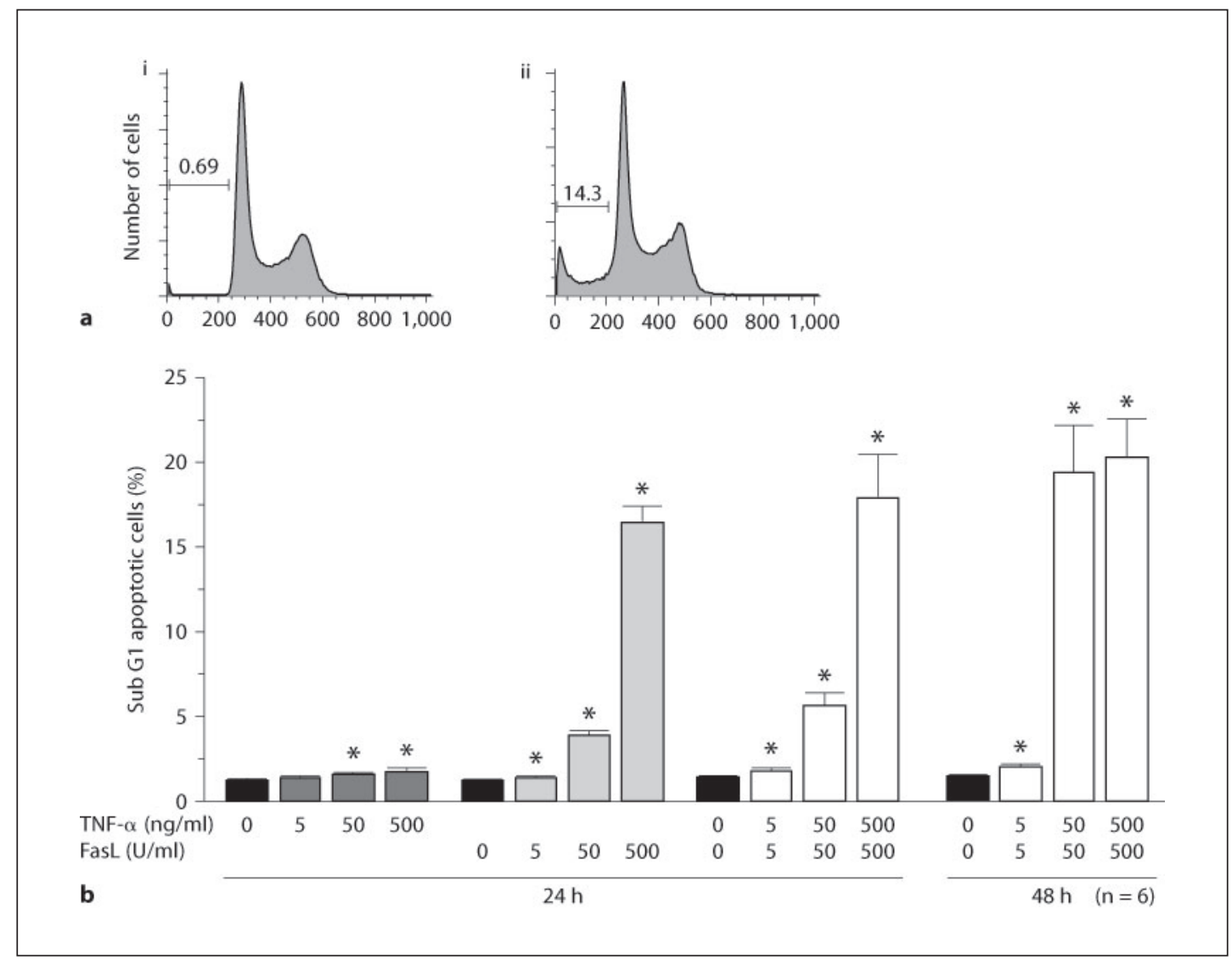

Fig. 4. Stimulation with FasL and TNF- $\alpha$ induced apoptosis of cultured tubular epithelial cells. Apoptotic cells were detected as a sub G1 population by FACS analysis following propidium iodide staining. Representative data of unstimulated cells (ai) and combined stimulation with FasL (500 U/ml) and TNF- $\alpha(500$ $\mathrm{ng} / \mathrm{ml}$ ) (aii). Quantification of the levels of apoptosis is shown in $\mathbf{b}$ following stimulation of cultured cells for $24 \mathrm{~h}$ with FasL and/or TNF- $\alpha$ at the indicated concentrations. Values are mean \pm SEM. ${ }^{*} \mathrm{p}<0.05$ compared with unstimulated control cells.

FasL with the expression level of Fas on tubular epithelial cells increased by cytokine treatment [25]. This local amplification system underlies the marked impact of the FasL/Fas system on inflammation. In contrast, mice with disrupted FasL/Fas systems are protected from tubular cell injury after ischemia reperfusion [11]. Thus, the effect of ischemia-reperfusion injury upon the FasL/Fas system acts to augment tissue destruction.

There are alternative explanations for the dominance of the FasL/Fas system over the TNF- $\alpha /$ TNFR system. FasL is able to induce NF- $\kappa B$ activation and IL- 8 production by a Fasassociated death domain protein (FADD)-dependent mechanism, which is distinctively regulated by TNF- $\alpha[2,26]$. The production of IL- 8 and other cytokines have been reported to participate in inflammatory reactions in the diseased kidney [20,27-29] and this may partly explain the difference between the FasL/Fas and TNF- $\alpha$ /TNFR1 pathways in vivo.

Our data demonstrated that FasL antibody diminished the number of apoptotic cells more than TNFR1 deficiency. FasL and TNF- $\alpha$ bind to Fas and TNFR1 with the apoptotic signal mediated by death domain-containing cytoplasmic proteins such as FADD and TNFR1-associated death domain protein (TRADD) [30, 31]. Both signaling cascades are initiated by different death domains and end in common activation of caspase 8. Although 

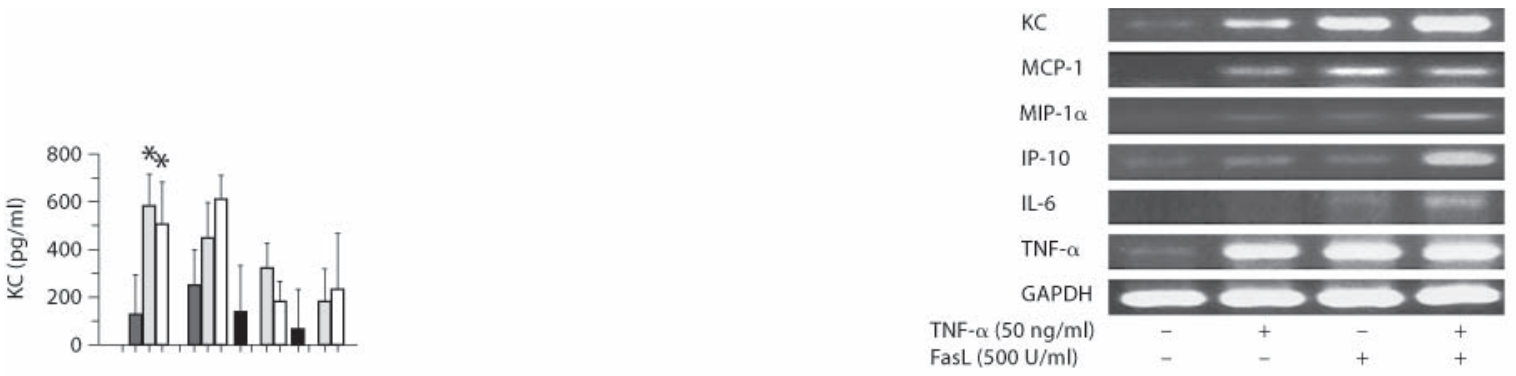
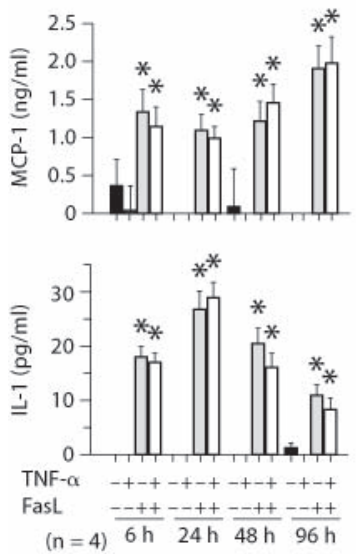
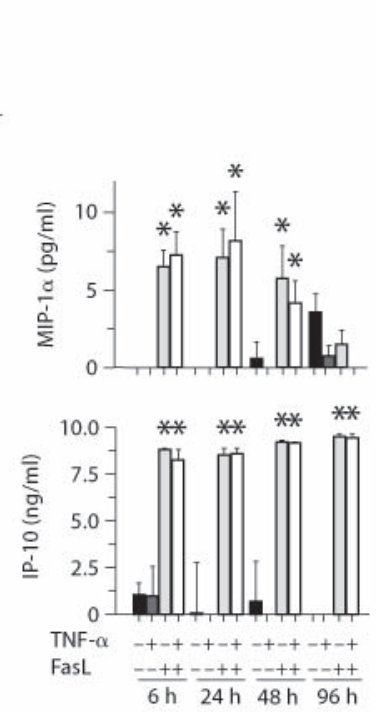

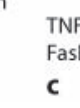
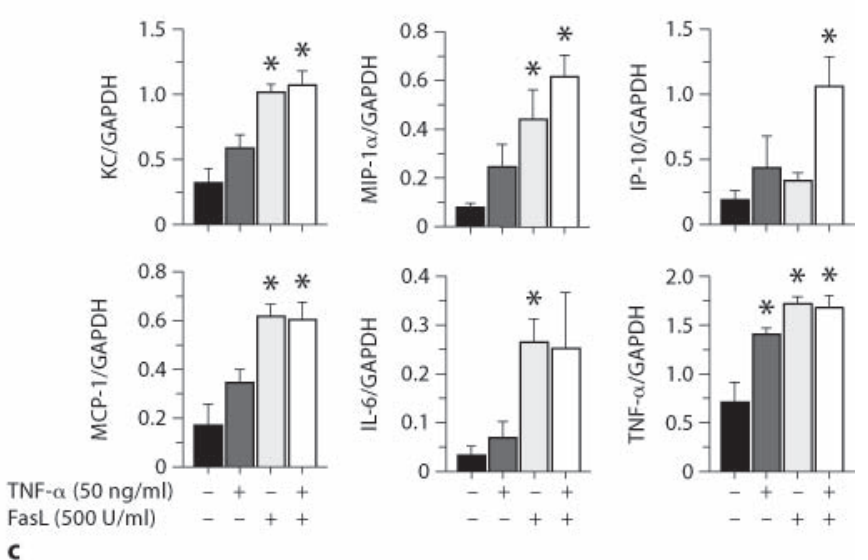

Fig. 5. Cytokine and chemokine expression by cultured tubular epithelial cells was increased following stimulation with FasL and/or TNF- $\alpha$. Cytokine/chemokine expression of cultured tubular epithelial cells was determined using a Procarta Cytokine Profiling kit and multiplex PCR. a Quantification of cytokines/chemokines was performed at the indicated time points. Representative data are shown in $\mathbf{b}$ for the indicated stimulation conditions. c Quantification of density of each band was normalized relative to GAPDH. The cultured cells were stimulated with FasL and/or TNF- $\alpha$ at the indicated concentrations for 24 h. Values are mean \pm SEM. ${ }^{*} \mathrm{p}<0.05$ compared with unstimulated control cells.

these two pathways seem similar, Fas-mediated cell death occurs much more rapidly than that triggered by TNFR1 [32]. In accordance with this work, we demonstrated that Fas-mediated apoptosis was dominant over TNFR1-mediated apoptosis in our model of renal ischemia-reperfusion injury. These findings were confirmed by our in vitro study. Further studies will be needed to reveal the precise molecular mechanisms of these differences between the Fas and TNFR1 pathway.

Although apoptosis and necrosis are well-characterized findings in ischemia-reperfusion injury, several alternative caspase-independent cell death pathways have been described [33]. For example, oncosis describes cell death that is characterized by cell swelling, organelle swelling, membrane blebbing and increased membrane permeability and may occur when ATP generation is attenuated or when cellular energy consumption becomes dysregulated [34]. These conditions are present in ischemia-reperfusion injury. Moreover, it was reported that oncosis is partially induced by Fas [35] and it might be reasonable to speculate that Fas participates in the pathogenesis of renal ischemia-reperfusion injury via the induction of oncosis. 
Although antibody administration and gene deletion are the two main intervention methods used in animal experiments, there are some differences between the two methods. Whereas gene deletion completely blocks the signal, antibody-mediated inhibition cannot completely block the effect as the antibody level decreases gradually after injection. However, gene deletion may induce other intrinsic compensatory systems. Moreover, we used TNFR1-deficient mice in the present study. TNF- $\alpha$ has two distinct receptors: TNF receptors with a molecular weight of $55 \mathrm{kDa}$ (TNFR1) and $75 \mathrm{kDa}$ (TNFR2). These two receptors show $30 \%$ identity at the amino acid level in their extracellular, cysteine-rich and ligand-binding regions. In the normal kidney, TNFR1 was abundant on infiltrating leukocytes in the interstitium and glomerular endothelium. Moreover, it was reported that TNFR1-deficient mice were resistant to lipopolysaccharide- or staphylococcal enterotoxin-induced shock with TNFR2-deficient mice being less sensitive. However, TNFR2 would have some effects in ischemic kidney injury and this is a limitation of our experiment. Further studies are required to evaluate these points further.

FasL and TNF- $\alpha$ induced both apoptosis and cytokine/chemokine production in cultured tubular epithelial cells. However, our in vivo studies indicated that FasL had the greater impact on apoptosis and inflammation in ischemic acute kidney injury compared to TNF$\alpha$. These findings indicate that the Fas/FasL system represents a useful therapeutic target for ischemic acute kidney injury.

\section{Acknowledgements}

This work was financially supported in part by Grants-in-Aids from the Ministry of Education, Culture, Sports, Science, and Technology of the Japanese Government.

\section{References}

-1 Mantell LL, Kazzaz JA, Xu J, Palaia TA, Piedboeuf B, Hall S, Rhodes GC, Niu G, Fein AF, Horowitz S: Unscheduled apoptosis during acute inflammatory lung injury. Cell Death Differ 1997;4:600-607.

-2 Imamura R, Konaka K, Matsumoto N, Hasegawa M, Fukui M, Mukaida N, Kinoshita T, Suda T: Fas ligand induces cell-autonomous nf-kappab activation and interleukin-8 production by a mechanism distinct from that of tumor necrosis factor-alpha. J Biol Chem 2004;279:46415-46423.

-3 Daemen MA, van 't Veer C, Denecker G, Heemskerk VH, Wolfs TG, Clauss M, Vandenabeele P, Buurman WA: Inhibition of apoptosis induced by ischemia-reperfusion prevents inflammation. J Clin Invest 1999;104:541-549.

-4 Kondo T, Suda T, Fukuyama H, Adachi M, Nagata S: Essential roles of the Fas ligand in the development of hepatitis. Nat Med 1997;3:409-413.

-5 Suzuki C, Isaka Y, Shimizu S, Tsujimoto Y, Takabatake Y, Ito T, Takahara S, Imai E: Bcl-2 protects tubular epithelial cells from ischemia reperfusion injury by inhibiting apoptosis. Cell Transplant 2008;17:223-229.

-6 Nakamoto Y, Kaneko S, Fan H, Momoi T, Tsutsui H, Nakanishi K, Kobayashi K, Suda T: Prevention of hepatocellular carcinoma development associated with chronic hepatitis by anti-fas ligand antibody therapy. J Exp Med 2002;196:1105-1111.

-7 Miwa K, Asano M, Horai R, Iwakura Y, Nagata S, Suda T: Caspase 1-independent IL-1beta release and inflammation induced by the apoptosis inducer Fas ligand. Nat Med 1998;4:1287-1292.

$\checkmark 8$ Vielhauer V, Mayadas TN: Functions of TNF and its receptors in renal disease: distinct roles in inflammatory tissue injury and immune regulation. Semin Nephrol 2007;27:286-308.

-9 Umemura M, Kawabe T, Shudo K, Kidoya H, Fukui M, Asano M, Iwakura Y, Matsuzaki G, Imamura R, Suda T: Involvement of IL-17 in Fas ligand-induced inflammation. Int Immunol 2004;16:10991108 . 
-10 Zhang HG, Fleck M, Kern ER, Liu D, Wang Y, Hsu HC, Yang P, Wang Z, Curiel DT, Zhou T, Mountz JD: Antigen presenting cells expressing Fas ligand down-modulate chronic inflammatory disease in Fas ligand-deficient mice. J Clin Invest 2000;105:813-821.

-11 Nogae S, Miyazaki M, Kobayashi N, Saito T, Abe K, Saito H, Nakane PK, Nakanishi Y, Koji T: Induction of apoptosis in ischemia-reperfusion model of mouse kidney: possible involvement of Fas. J Am Soc Nephrol 1998;9:620-631.

-12 Ortiz A, Lorz C, Egido J: The Fas ligand/Fas system in renal injury. Nephrol Dial Transplant 1999; 14:1831-1834.

-13 Zager RA, Johnson AC, Lund S: Uremia impacts renal inflammatory cytokine gene expression in the setting of experimental acute kidney injury. Am J Physiol Renal Physiol 2009;297:F961-F970.

- 14 Furuichi K, Wada T, Iwata Y, Kokubo S, Hara A, Yamahana J, Sugaya T, Iwakura Y, Matsushima K, Asano M, Yokoyama H, Kaneko S: Interleukin-1-dependent sequential chemokine expression and inflammatory cell infiltration in ischemia-reperfusion injury. Crit Care Med 2006;34:2447-2455.

-15 Rothe J, Lesslauer W, Lotscher H, Lang Y, Koebel P, Kontgen F, Althage A, Zinkernagel R, Steinmetz $\mathrm{M}$, Bluethmann $\mathrm{H}$ : Mice lacking the tumour necrosis factor receptor 1 are resistant to TNF-mediated toxicity but highly susceptible to infection by listeria monocytogenes. Nature 1993;364:798802.

-16 Miwa K, Hashimoto H, Yatomi T, Nakamura N, Nagata S, Suda T: Therapeutic effect of an anti-Fas ligand $\mathrm{mAB}$ on lethal graft-versus-host disease. Int Immunol 1999;11:925-931.

- 17 Suda T, Tanaka M, Miwa K, Nagata S: Apoptosis of mouse naive T cells induced by recombinant soluble Fas ligand and activation-induced resistance to Fas ligand. J Immunol 1996;157:3918-3924.

- 18 Ishimaru N, Yanagi K, Ogawa K, Suda T, Saito I, Hayashi Y: Possible role of organ-specific autoantigen for Fas ligand-mediated activation-induced cell death in murine Sjögren's syndrome. J Immunol 2001;167:6031-6037.

-19 Furuichi K, Wada T, Iwata Y, Sakai N, Yoshimoto K, Kobayashi Ki K, Mukaida N, Matsushima K, Yokoyama H: Administration of FR167653, a new anti-inflammatory compound, prevents renal ischaemia/reperfusion injury in mice. Nephrol Dial Transplant 2002;17:399-407.

-20 Wada T, Tomosugi N, Naito T, Yokoyama H, Kobayashi K, Harada A, Mukaida N, Matsushima K: Prevention of proteinuria by the administration of anti-interleukin 8 antibody in experimental acute immune complex-induced glomerulonephritis. J Exp Med 1994;180:1135-1140.

-21 Takaya K, Koya D, Isono M, Sugimoto T, Sugaya T, Kashiwagi A, Haneda M: Involvement of ERK pathway in albumin-induced MCP-1 expression in mouse proximal tubular cells. Am J Physiol Renal Physiol 2003;284:F1037-F1045.

-22 Cursio R, Filippa N, Miele C, Colosetti P, Auberger P, Van Obberghen E, Gugenheim J: Fas ligand expression following normothermic liver ischemia-reperfusion. J Surg Res 2005;125:30-36.

-23 Ortiz-Arduan A, Danoff TM, Kalluri R, Gonzalez-Cuadrado S, Karp SL, Elkon K, Egido J, Neilson EG: Regulation of Fas and Fas ligand expression in cultured murine renal cells and in the kidney during endotoxemia. Am J Physiol 1996;271:F1193-F1201.

-24 Green DR, Ferguson TA: The role of Fas ligand in immune privilege. Nat Rev Mol Cell Biol 2001;2: 917-924.

-25 Du C, Jiang J, Guan Q, Yin Z, Masterson M, Parbtani A, Zhong R, Jevnikar AM: Renal tubular epithelial cell self-injury through Fas/Fas ligand interaction promotes renal allograft injury. Am J Transplant 2004;4:1583-1594.

-26 Kreuz S, Siegmund D, Rumpf JJ, Samel D, Leverkus M, Janssen O, Hacker G, Dittrich-Breiholz O, Kracht M, Scheurich P, Wajant H: NFkappaB activation by fas is mediated through FADD, caspase-8, and RIP and is inhibited by FLIP. J Cell Biol 2004;166:369-380.

-27 Wada T, Yokoyama H, Furuichi K, Kobayashi KI, Harada K, Naruto M, Su SB, Akiyama M, Mukaida $\mathrm{N}$, Matsushima K: Intervention of crescentic glomerulonephritis by antibodies to monocyte chemotactic and activating factor (MCAF/MCP-1). FASEB J 1996;10:1418-1425.

28 Furuichi K, Wada T, Kaneko S, Murphy PM: Roles of chemokines in renal ischemia/reperfusion injury. Front Biosci 2008;13:4021-4028.

-29 Furuichi K, Kaneko S, Wada T: Chemokine/chemokine receptor-mediated inflammation regulates pathologic changes from acute kidney injury to chronic kidney disease. Clin Exp Nephrol 2009;13: 9-14.

-30 Boldin MP, Goncharov TM, Goltsev YV, Wallach D: Involvement of mach, a novel MORT1/FADDinteracting protease, in Fas/APO-1- and TNF receptor-induced cell death. Cell 1996;85:803-815. 
Furuichi et al.: FasL and TNF- $\alpha$ in Ischemic Acute Kidney Injury

-31 Hsu H, Xiong J, Goeddel DV: The TNF receptor 1-associated protein TRADD signals cell death and NF-kappa B activation. Cell 1995;81:495-504.

-32 Clement MV, Stamenkovic I: Fas and tumor necrosis factor receptor-mediated cell death: similarities and distinctions. J Exp Med 1994;180:557-567.

-33 Tang PS, Mura M, Seth R, Liu M: Acute lung injury and cell death: how many ways can cells die? Am J Physiol Lung Cell Mol Physiol 2008;294:L632-L641.

-34 Majno G, Joris I: Apoptosis, oncosis, and necrosis. An overview of cell death. Am J Pathol 1995; 146: 3-15.

- 35 Zhu J, Okumura H, Ohtake S, Nakamura S, Nakao S: The molecular mechanism of arsenic trioxideinduced apoptosis and oncosis in leukemia/lymphoma cell lines. Acta Haematol 2003;110:1-10. 